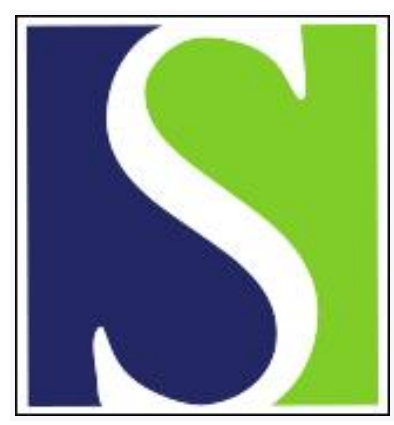

Scand J Work Environ Health 1976;2(3):140-146

https://doi.org/10.5271/sjweh.2810

Issue date: Sep 1976

Neurophysiological findings among workers occupationally exposed to styrene.

by Seppäläinen AM, Härkönen $\mathrm{H}$

Key terms: EEG; electroencephalography; electroneuromyography; encephalopathy; mancelic acid; neurophysiological finding; occupational exposure; styrene; worker

This article in PubMed: www.ncbi.nlm.nih.gov/pubmed/973127

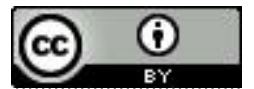




\title{
Neurophysiological findings among workers occupationally exposed to styrene
}

\author{
by ANNA MARIA SEPPÄLÄINEN, M.D., and HANNU HÄRKÖNEN, M.D. ${ }^{1}$
}

\begin{abstract}
SEPPÄLÄINEN, A. IM. and HÄRKÖNEN, H. Neurophysiological findings among workers occupationally exposed to styrene. Scand. j. work environ. \& health 3 : (1976) $140-146$. Ninety-six male workers occupationally exposed to styrene in 24 plants producing reinforced polyester plastic products were studied neurophysiologically. The mean age of the subjects was $29.6 \pm 7.4$ years, and the duration of the exposure varied from 6 months to 14 years (mean 5.0 years). Mandelic acid concentration in the urine (mean of five values determined during five consecutive weeks) was used as the measure of exposure. The individual means of the mandelic acid concentrations varied from 7 to $4,715 \mathrm{mg} / \mathrm{dm}^{3}$ (median $808 \mathrm{mg} / \mathrm{dm}^{3}$ ). Neurotoxic effects of styrene exposure upon the central nervous system were revealed by abnormalities in the EEG. The overall prevalence of abnormal EEGs was $24 \%$ (23 out of 96 ), which is higher than that found among a normal population $(p<0.05)$. Abnormal EEGs were found in one-third of the subjects with relevant styrene exposure (mandelic acid concentration over $700 \mathrm{mg} / \mathrm{dm}^{3}$ ), while low-leveI styrene exposure did not increase the prevalence of normal EEGs above that found in a normal population. Nerve conduction velocity measurements performed on 40 subjects did not reveal any definite relationship between neuropathy and styrene exposure. The EEG examination is useful in the investigation of the neurotoxic effects of styrene. Whenever a possibility exists of excessive styrene exposure or beginning poisoning, the workers should be submitted to an EEG examination.
\end{abstract}

Key words: styrene, electroencephalography, encephalopathy, electroneuromyography, mandelic acid.

Styrene is widely used both as a solvent and as a curing agent in the reinforced polyester plastic industry. Spencer et al. (19) showed that monometric styrene in high concentrations is capable of producing central nervous depression in rats and guinea pigs. Wolf et al. (22) concluded, from their animal experiments, that styrene has a relatively low toxicity in long-term exposure but that complaints of disagreeable odor or eye and nasal irritation would make it necessary to keep the concentration below $100 \mathrm{ppm}$ in a

1 Department of Occupational Medicine, Institute of Occupational Health, Helsinki, Finland.

Reprint requests to: Dr. A. M. Seppäläinen, Institute of Occupational Health, Haartmaninkatu 1, FIN-00290 Helsinki 29, Finland. work area. On the other hand Roth and Klimková-Deutschová (11) reported that styrene in occupational exposure induces EEG abnormalities more often than several other chemicals.

The reinforced polyester plastic industry is nowadays relatively large; for example, in 1974 in Finland about 1,700 workers were exposed to styrene in 175 plants. Thus knowledge of the effects of styrene on the nervous systems is important. Because neurophysiological methods have proved sensitive in showing the neurotoxic effects of several industrial chemicals (14), we decided to apply such methods in an examination of styrene exposed workers.

The present neurophysiological study is a part of a larger project investigating the hazards of occupational styrene exposure. 
Our objective is to reveal nervous system effects among workers occupationally exposed to styrene and to try to establish a dose-effect relationship.

\section{MATERIAL AND METHODS}

\section{Subjects}

The subjects of the study consisted of 96 male laminating workers from 24 factories manufacturing polyester plastic products. The age of the workers varied from 16 to .54 years (mean 29.6 years, SD 7.4), and their duration of exposure from 0.5 to 14 years (mean 5.0 years, SD 3.2). All the workers spread the polyester resin by hand.

The workers' health history was ascertained by a questionnaire. They were given a clinical and psychological examination in addition to the neurophysiological studies made. None of the workers had diabetes, epilepsy, or a history of unconsciousness lasting more than $30 \mathrm{~min}$.

Thirty healthy males with a similar age distribution (mean age 29.6 years, SD 5.6) served as controls for the nerve conduction studies. The control subjects had had no occupational exposure to neurotoxic chemicals.

\section{Exposure}

In order to determine the current level of exposure the urinary mandelic acid concentration was measured with either a colorimetric (5) or a gas chromatographic method (4). The results of the colorimetric determinations were transformed to the same scale as the gas chromatographic results (4). The urine samples for the mandelic acid determinations were collected from every subject after an 8-h work day once a week, but on different days, for five consecutive weeks prior to the clinical examination. The mean of the five determinations was used in the estimation of the intensity of styrene exposure. The individual means of the mandelic acid concentrations varied from 7 to $4,715 \mathrm{mg} / \mathrm{dm}^{3}$, and the group median was $808 \mathrm{mg} / \mathrm{dm}^{3}$.

\section{Neurophysiological methods}

Electroencephalograms of all the subjects were registered for $30 \mathrm{~min}$ with an 8-channel Elema Mingograph using 21 electrodes placed according to the international $10-20$ system. Hyperventilation for $3 \mathrm{~min}$ and photic stimulation were the activation methods. No sedation was used. If the subjects spontaneously fell asleep, they were allowed to sleep for no longer than half of the registration period.

One of us (AMS) interpreted the EEGs according to the usual criteria (7) and without knowledge of the exposure level. The abnormalities were graded accordin $r$ to previously described principles (12). Vigilance during the recording was evaluated and classed as follows: (a) wakefulness, (b) slight lowering of vigilance $=$ attenuation of alpha activity, (c) drowsiness (sleep stage I) $=$ prevalence of theta activity as background activity, (d) light sleep (sleep stage II) = appearance of sleep spindles. Deeper stages of sleep did not occur in the EEG records. Possible beta activity was noted, and we also gathered information on the drugs which the subjects had used during the week prior to the EEG examination.

Nerve conduction velocity studies were performed on 40 of the subjects with the most subjective complaints. The mean age of these persons was 29.6 years (SD 7.9). Their individual mean mandelic acid concentration varied from 30 to $3,811 \mathrm{mg} / \mathrm{dm}^{3}$ (median $851.5 \mathrm{mg} / \mathrm{dm}^{3}$ ). The nerve conduction velocity studies included the maximal motor conduction velocity (MCV) of the median, ulnar, deep peroneal and posterior tibial nerves, the conduction velocity of the slower motor fibers (CVSF) of the ulnar and deep peroneal nerves, and the sensory conduction velocity (SCV) of the median and ulnar nerves. The measurements were made with a Disa electromyograph and stimulator with skin electrodes according to usual methods (15, 17). For SVCs an averaging technique was applied using a Nokia Pulse Analyser (16). All the measurements were made in the same warm $\left(25-26^{\circ} \mathrm{C}\right)$ laboratory, and skin temperature was recorded. 
Table 1. EEG findings among 96 styrene exposed workers.

\begin{tabular}{lc}
\hline Finding & Number \\
\hline Normal & 73 \\
Diffuse theta activity & 8 \\
Local slow activity & 14 \\
Bilateral S\&W discharges & 2 \\
\hline
\end{tabular}

\section{RESULTS}

\section{Electroencephalograms}

Twenty-three of the 96 EEGs studied displayed some abnormality, usually mild. The abnormality (table 1) was excessive diffuse theta activity in 8 cases and localized slow waves in 14 cases, 9 of the latter being slow wave abnormality in the posterior regions. Two subjects showed bilateral spike and wave (S\&W) discharges activated also by photic stimulation; one of them also had a focal slow wave abnormality.

The prevalence of abnormal EEGs among workers with long-term styrene exposure was thus clearly higher than that $(10 \%)$ found for normal populations cited in EEG literature (binomial distribution, $\mathrm{p}<0.01$ ).

The mandelic acid concentration (mean of 5 measurements) of the subjects with abnormal EEGs was higher (median 975 $\mathrm{mg} / \mathrm{dm}^{3}$ ) than that of subjects with normal EEGs (median $750 \mathrm{mg} / \mathrm{dm}^{3}$ ) (Wilcoxon test, $\mathrm{u}=1.97, \mathrm{p}<0.05$ ) (fig. 1).

A certain threshold for response was noted at the level of $700 \mathrm{mg} / \mathrm{dm}^{3}$ of mandelic acid. Also calculations of sensitivity and specificity supported the choice of this cut-off point. Among the 38 workers with a mandelic acid concentration of less than $700 \mathrm{mg} / \mathrm{dm}^{3}$, only four had abnormal EEGs (about $10 \%$ ), while among the 58 workers with higher mandelic acid concentrations $19(33 \%)$ showed EEG abnormalities (table 2). The proportion of abnormal EEGs did not increase among those with a mandelic acid concentration of more than $2,000 \mathrm{mg} / \mathrm{dm}^{3}$. However, there was a limited number of workers with such a high exposure level.
We also compared the final (fifth) mandelic acid concentration to the EEG result. This mandelic acid concentration tended to be higher for subjects with abnormal EEGs than for those with normal EEGs, but the difference was not statistically significant.

The duration of exposure of workers with abnormal EEGs was similar to that of subjects with normal EEGs. Thus longer exposure did not increase the prevalence of EEG abnormalities. On the other hand workers exposed for less than 5 years had a higher mandelic acid con-

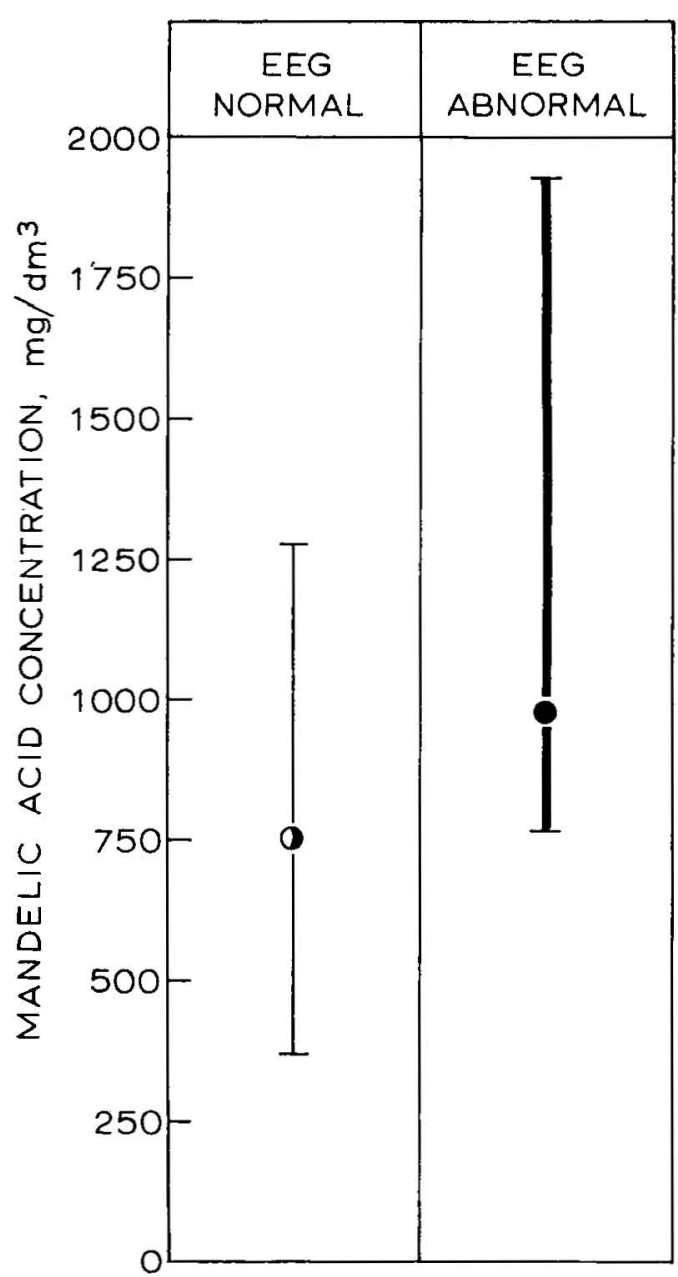

Fig. 1. Mandelic acid concentration (median and 25 and 75 percentiles) in the urine and the EEG findings among 96 styrene exposed workers (73 with normal and 23 with abnormal EEGs). 
centration than those exposed for a longer time (Kolmogorov-Smirnov two sample test, $\mathrm{p}<0.05$ ).

The mean age of the subjects with normal EEGs was 29.5 years (SD 6.9), and that of those with abnormal EEGs was 30.0 years (SD 9.1). The ages of subjects in different exposure levels and with normal or abnormal EEGs was also similar. The age of subjects with a mandelic acid concentration below $700 \mathrm{mg} / \mathrm{dm}^{3}$ was slightly higher (mean 31.4 years, SD 5.2) than the age of subjects with higher exposure (mean 28.5 years, SD 8.3).

We did not try to keep the subjects awake throughout the EEG recording, as natural sleep may be considered an activation method. Forty-four of the 96 subjects stayed awake, 11 showed a lowering of vigilance with short episodes of attenuation of alpha activity, 30 entered sleep stage I, and 11 sleep stage II. Subjects with abnormal EEGs did not sleep more often than the ones with normal EEGs The subjects showing sleep stage II tended to have a higher mandelic acid concentration than the others, but the difference was statistically significant only between those with sleep stage II and those with sleep stage $I$.

\section{Electroneuromyographic studies}

As a group the styrene workers did not differ from the age-standardized normal control group from our laboratory files in any conduction velocity measure (table 3 ). Slightly abnormal values in one or more nerve conduction velocities were encountered in 9 cases out of the 40 subjects studied. Five subjects revealed signs of mononeuropathy. Two of these cases could be definitely explained by an etiology other than styrene, in two cases another etiology was strongly suspected, but in the remaining case we could not find a cause for mononeuropathy. Four subjects displayed abnormalities in at least two nerves, a finding which suggests polyneuropathy. One of them assumably had alcoholic polyneuropathy, but in the remaining three cases no apparent etiology for polyneuropathy could be revealed. As the four subjects with neuropathic signs without a known etiology had had rather
Table 2. EEG findings among 96 styrene exposed workers according to individual mean concentrations $\left(\mathrm{mg} / \mathrm{dm}^{3}\right)$ of mandelic acid. The prevalence of abnormal EEGs was higher among those whose mandelic acid concentration was over $700 \mathrm{mg} / \mathrm{dm}^{3}\left(\chi^{2}=6.22\right.$, df $\left.2, \mathrm{p}<0.05\right)$.

\begin{tabular}{|c|c|c|c|}
\hline \multirow{2}{*}{$\begin{array}{l}\text { Mandelic acid } \\
\text { concentration }\end{array}$} & \multicolumn{2}{|c|}{ EEG finding } & \multirow{2}{*}{ Total } \\
\hline & Normal & Abnormal & \\
\hline$\leq \quad 699$ & 34 & 4 & 38 \\
\hline $7 \overline{00}-1,999$ & 29 & 14 & 43 \\
\hline $2,000-4,779$ & 10 & 5 & 15 \\
\hline Total & 73 & 23 & 96 \\
\hline
\end{tabular}

Table 3. Means and standard deviations (SD) of the maximal motor conduction velocities (MCV), sensory conduction velocities (SCV), and conduction velocity of the slower motor fibers (CVSF) of 40 styrene exposed workers and 30 male controls with the same age range. The velocities are given in meters per second. The difference between the groups was not statistically significant for any measure.

\begin{tabular}{lrrrrr}
\hline \multirow{2}{*}{$\begin{array}{l}\text { Nerve and } \\
\text { velocity }\end{array}$} & \multicolumn{2}{c}{ Exposed } & & \multicolumn{2}{c}{ Controls } \\
\cline { 6 - 6 } & Mean & SD & & Mean & SD \\
\hline Median nerve & & & & \\
$\quad$ MCV & 60.3 & 6.5 & & 59.0 & 2.8 \\
SCV & 60.1 & 5.1 & & 61.6 & 4.8 \\
Ulnar nerve & & & & & \\
$\quad$ MCV & 62.1 & 6.4 & & 57.8 & 4.0 \\
SCV & 59.1 & 6.4 & & 60.4 & 6.1 \\
CVSF & 43.3 & 4.6 & & 45.5 & 3.2 \\
Deep peroneal nerve & & & & \\
$\quad$ MCV & 51.2 & 5.8 & & 51.6 & 3.5 \\
$\quad$ CVSF & 38.4 & 3.6 & & 38.2 & 5.6 \\
Posterior tibial nerve & & & & \\
MCV & 47.6 & 4.6 & & 47.5 & 5.4 \\
\hline
\end{tabular}

low mandelic acid concentrations, no close connection between styrene exposure and neuropathy can be claimed.

\section{DISCUSSION}

EEG abnormalities are found in brain dysfunctions already at the biochemical level, and anatomical damage does not necessarily accompany them. According to EEG literature about $10 \%$ of "normal" populations shows EEG abnormalities, usually in the form of slow waves (7). Previous studies from this institute (16) 
have shown the prevalence of EEG abnormalities among industrial workers without known chemical exposure to be close to $10 \%$; for example 6 out of 50 paper mill workers had abnormal EEGs.

Abnormal EEGs have been described previously in connection with exposure to industrial solvents like benzene (18), methylene chloride (6), carbon disulfide $(16,21)$ as well as in mixed solvent exposure (13). The reported prevalences of EEG abnormalities varied from 35 up to 75 and $80 \%$. It is difficult to compare the actual prevalences of EEG abnormalities in different types of exposure because the prevalence also reflects the degree of exposure and/or poisoning. The graver the exposure, the higher the frequency of abnormal EEGs (13). In actual poisoning cases an abnormal EEG is a very frequen $t$ finding. A prevalence of up to $75 \%$ has been connected to comparably high exposure to some industrial solvents (13), but the subjects were often suffering from at least mild poisoning and had sought medical help.

According to Stewart et al. (20) human volunteers experienced significant subjective symptoms, had abnormal results on a modified Romberg test, and showed some deterioration in certain psychological tests during $1 \mathrm{~h}$ of exposure to $375 \mathrm{ppm}$ of styrene. But exposure to $200 \mathrm{ppm}$ for $1 \mathrm{~h}$ or to $100 \mathrm{ppm}$ for up to $7 \mathrm{~h}$ did not induce objective signs of neurological or psychological impairment. However, subjectively, three subjects out of six experienced intermittent difficulty in performing the modified Romberg test on one or two occasions out of eight during 7-h exposure to $100 \mathrm{ppm}$ of styrene. One cannot, however, use short-term exposure experiments to draw conclusions concerning safety during long-term occupational exposure.

Some case reports have mainly described neurasthenic symptoms in occupational styrene exposure $(1,8)$. Klimková-Deutschová (8) also reported abnormal EEG findings in 13 of the 18 EEGs from the 17 persons studied. The EEGs of both the Swedish cases with neurasthenic symptoms were reported to be normal (1).

In other papers Roth and KlimkováDeutschová (11) and Klimková-Deutschová et al. (9) have regarded the EEG as a good tool in the study of styrene effects. Nine out of 14 styrene exposed women had abnormal EEGs (11). The abnormalities were theta waves either diffusely in the whole record or predominantly in the frontal part, usually only during hyperventilation, but at times in the resting record also. During a follow-up period of 3 years (9) the EEG deteriorated noticeably. An increased tendency to sleep during the EEG recording was also considered typical of styrene effect.

Dolmierski et al. (2) reported that $68 \%$ of 60 workers with occupational styrene exposure had abnormal EEGs. Thirteen per cent showed borderline findings, and only $18 \%$ had normal EEG records. The abnormalities often had paroxysmal characteristics with high voltage sharp waves. The abnormalities were usual among young workers with short exposure, but only three persons of their series had been exposed for over 5 years. The exposure level was not clearly defined. The authors stated, however, that styrene metabolites in the urine were five times the permissible amount in Poland. Simultaneously with styrene these workers were also exposed to toluene.

The prevalence of abnormal EEGs (23 out of 96) among styrene exposed workers in the present study was higher than expected for a normal population, but lower than that reported in the previously cited studies. This difference may be partly due to differences in interpretation; for example, we have regarded symmetrically distributed slow waves during hyperventilation as a normal phenomenon (7). Light sleep often occurs during EEG recording in our EEG laboratory, even among subjects without any chemical exposure. Neither could we prove any relevant correlation between mandelic acid concentration and sleep phenomina.

The subjects with EEG abnormalities had higher mean mandelic acid concentrations than the ones with normal EEGs. A dose-response relationship is also indicated by the fact that workers with a low level of exposure (mandelic acid concentration less than $700 \mathrm{mg} / \mathrm{dm}^{3}$ ) had the same proportion of abnormal EEGs as that found in the normal population (4 out of 38), while among workers with higher styrene exposure the prevalence of abnormal EEGs was threefold, i.e., $33 \%$ (19 out of 58 ). 
The prevalence of abnormal EEGs that we found among styrene exposed workers was relatively low in comparison to that found in earlier reports on other chemical exposures and the EEG. Abnormal EEGs have been shown to be frequent among actual poisoning cases. An earlier study (16) from our institute dealt with the neurotoxicity of carbon disulfide. In that study $39 \%$ of 54 workers with a longterm (median 15 years) exposure to carbon disulfide had abnormal EEGs. The latter frequency of abnormal EEGs is not markedly deviant from what was found in the present study.

The longer exposure (above 5 years) did not increase the prevalence of abnormal EEGs, but, on the other hand, the mandelic acid concentration was lower among longer exposed workers. This finding may indicate that workers with higher exposure and/or symptoms do not stay in high exposure; they either move away or are promoted to more skilled work with less exposure. The same conclusion could also be drawn from the fact that the subjects with a low exposure level were slightly older than those with a high level. The age of the subjects with abnormal EEGs did not differ however from that of the subjects with normal EEGs, not even when the exposure level was taken into account

The localization of the EEG abnormalities among the styrene exposed workers in the present study was often diffuse or generalized. If the slow wave abnormalities were localized, the site was often in the posterior regions. The latter may be based on the relatively young age of many of the subjects because among young persons EEG abnormalities tend to be localized in the posterior brain areas. Most of the abnormalities were slow waves, but in two cases we found bilateral spike and wave discharges, a generalized paroxysmal abnormality. As two previous papers (2, 8) also reported on paroxysmal sharp waves in EEGs of styrene exposed workers, it is possible that styrene may induce irritative brain lesions.

At least $20 \mathrm{~h}$ had passed since the last exposure to styrene before the EEG recording. Hence the EEG abnormalities cannot be regarded as acute effects of styrene. On the basis of the present study we cannot say how long EEG abnormalities remain after exposure ceases.

The mandelic acid concentration in the urine sample taken immediately after an 8-h work shift correlated well to the 8-h time-weighted average (TWA) of styrene exposure (3). Mandelic acid concentration can be regarded as a biological exposure measure and thus reflects individual exposure even better than overall air concentrations in the work area. According to the mandelic acid determinations the estimated mean TWA of styrene exposure of the studied group was about 30 ppm (3).

Among the most frequent subjective symptoms were tiredness and giddiness, and these symptoms can be related to the central nervous system. The physiological tests also revealed slight cerebral dysrunctions, and among them visuomotor inaccuracy was related to high mandelic acid concentration (10). Since the visual cortex is situated in the occipital region and the EEG abnormalities found were relatively frequent in the posterior regions. certain localizatory similarities exist between EEG abnormalities and psychological impairment.

At the exposure level of the present study we could not prove that styrene induces adverse effects upon peripheral nerves even though occasional cases of neuropathy following styrene exposure have been reported in the literature (8). Symptoms of peripheral nerve dysfunction were not reported by styrene workers, neither did their nerve conduction velocities as a group differ from values of normal unexposed controls. In half of the few cases with one or more nerve conduction velocities below the normal limit an etiological factor for neuropathy could be found or was suspected. In the remaining cases the exposure level was not high. In industry or private life workers are probably exposed to unidentifiable factors with mild noxious effects upon the peripheral nerves since a slowing of nerve conduction velocities can be found in "normal" populations (16).

According to the present study slight dysfunctions within the central nervous system belong to the first signs of styrene effect. Thus, if harmful effects upon 
health in styrene exposure are suspected, EEG examination should be included in the medical examination.

\section{ACKNOWLEDGMENTS}

The authors wish to thank Sisko Asp, M.Sc., for making the statistical calculations.

\section{REFERENCES}

1. AXELSON, O., FROBB̈̈J, G. and WEDEFELT, U. Kan styren exposition orsaka cerebroläsionella tillstånd? Läkartidningen 71 (1974): 3, 137-138.

2. DOLMIERSKI, R., KWIATKOWSKI, S. R. and NITKA, J. A preliminary evaluation of the studies on central nervous system in workers exposed to styrene. Bull. inst. mar. med. Gdansk 25 (1974): 2-3-4, 399406.

3. ENGSTRÖM, K., HÄRKÖNEN, H., KALLIOKOSKI, P. and RANTANEN, J. Urinary mandelic acid concentration after occupational exposure to styrene and its use as a biological exposure test. Scand. j. work. environ. \& health 2 (1976) $21-26$.

4. ENGSTRÖM, $K$. and RANTANEN, J. A new gas chromatographic method for determination of mandelic acid in urine. Int. Arch. Arbeitsmed. 33 (1974) 163-167.

5. HÄRKÖNEN, H., KALLIOKOSKI, P., HIETALA, S. and HERNBERG, S. Concentrations of mandelic acid and phenylglyoxylic acid in urine as indicators of styrene exposure. Work-environ.-health 11 (1974) $162-169$.

6. HANKE, C., RUPPE, K. and OTTO, J. Untersuchungsergebnisse zur toxischen Wirkung von Dichlormethan bei Fussbodenlegern. Z. Gesamte Hyg. 20 (1974) $81-84$.

7. KILOH, L. G. and OSSELTON, J. W. Clinical electroencephalography. (2nd ed.), Butterworths, London, 1966, $147 \mathrm{p}$.

8. KLIMKOVA-DEUTSCHOVA, E. Neurologische Befunde in der Plastikindustrie bei Styrol-Arbeitern. Int. Arch. Gewerbepath. Gewerbehyg. 19 (1962) 35-50.

9. KLIMKOVÁ-DEUT'SCHOVÁ, E., JANDOVA, Z., SALCMANOVA, K., SCHWARTZOVÁ, O. and TITMAN, O. Novější poznatky $\mathrm{k}$ neurologickému obrazu pracujících se styrenem [Recent advances concerning the clinical picture of professional styrene exposure]. Česk. neurol. neurochir. 36 (1973): 1, 20-25. (English summary)

10. LINDSTRÖM, K., HÄRKÖNEN, H. and HERNBERG, S. Disturbances in psychological functions of workers occupationally exposed to styrene. Scand. j. work. environ. \& health 3 (1976) 129-139.

11. ROTH, B. and KLIMKOVA-DEUTSCHO$\mathrm{VA}, \mathrm{E}$. The effect of the chronic action of industrial poisons on the electroencephalogram of man. Rev. czech. med. 9 (1963): 4, 217-227.

12. SEPPÄLAINEN, A. M. An electroencephalographic follow-up study of cardiac surgery patients. Doctoral dissertation, University of Helsinki, Helsinki 1973. $61 \mathrm{p}$.

13. SEPPÄLÄINEN, A. M. Neurotoxic effects of industrial solvents. Electroencephalogr. clin. neurophysiol. 34 (1973) 702-703.

14. SEPPÄLÄINEN, A. M. Applications of neurophysiological methods in occupational medicine: A review. Scand. j. work environ. \& health 1 (1975) $1-14$.

15. SEPPÄLÄINEN, A. M. and HERNBERG, S. Sensitive technique for detecting subclinical lead neuropathy. Br. j. ind. med. 29 (1972) 443-449.

16. SEPPÄLÄINEN, A. M. and TOLONEN, M. Neurotoxicity of long-term exposure to carbon disulfide in the viscose rayon industry: A neurophysiological study. Work-environ.-health 11 (1974) 145-153.

17. SMORTO, M. P. and BASMAJIAN, J. V. Clinical electroneurography. Williams \& Wilkins Co., Baltimore, Md. 1972. 234 p.

18. SOBCZYK, W., SIEDLECKA, B., GAJEWSKA, Z., HORYD, W. and DE MEZER O. Badania EEG u robotnic naražonych na styczność ze związkami benzenu [EEG recordings in workers exposed to benzene compounds]. Med. pr. 24 (1973) 273-283. (English summary)

19. SPENCER, H. C., IRISH, D. D., ADAMS, E. M. and ROWE, V. K. The response of laboratory animals to monomeric styrene. J. ind. hyg. 24 (1942): 10, 295-301.

20. STEWART, R. D., DODD, H. C., BARETTA, E. D. and SCHAFFER, A. W. Human exposure to styrene vapor. Arch. environ. health 16 (1968): 5, 656-662.

21. STÝBLOVÁ, V. and HOLANOVA, V. The electroencephalogram of workers exposed to carbon disulfide. Prac. lék. 25 (1973) 90-96.

22. WOLF, M. A, ROWE, V. K., MC COLLISTER, D. D., HOLLINGSWORTH, R. L. and OYEN, F. Toxicological studies of certain alkulated benzenes and benzene. Arch. ind. health 14 (1956) 387-398. 